Nanda Kumar MD MNAMS, Y.K. Batra MD MNAMS, Indu Bala MD, S. Gopalan FRCOG PhD

\title{
Nifedipine attenuates the hypertensive response to tracheal intubation in pregnancy-induced hypertension
}

Thirty women with pregnancy-induced hypertension (PIH) scheduled for Caesarean section under general anaesthesia were studied to evaluate the efficacy of sublingual nifedipine in attenuating the pressor response to laryngascopy and tracheal intubation. The patients were randomly given either the contents of a nifedipine capsule $10 \mathrm{mg}$ or placebo sublingually $20 \mathrm{~min}$ before induction of anaesthesia. Blood pressure and heart rate were recorded at various time intervals. There was a decrease in mean arterial blood pressure (MAP) after pretreatment with nifedipine $(P<0.01)$. The increase in $M A P$ during laryngoscopy and intubation was higher in the control group compared with nifedipine pretreatment group $(P<0.01)$. During laryngoscopy and intubation, MAP decreased by 3 $\mathrm{mmHg}$ in the nifedipine pretreatment group, while there was an increase of $14 \mathrm{mmHg}$ in the control group. Heart rate increased in both the groups during the laryngoscopy and tracheal intubation $(P<0.01)$ but the increase was higher in the nifedipine group than in the control group $(P<0.05)$. Neonatal Apgar scores in both the groups were comparable. These results suggest that sublingual nifedipine is effective in attenuating the hypertensive response to laryngoscopy and intubation but not the tachycardiac response in parturients with PIH.

L'efficacité de la néfidipine administrée en sublingual pour atténuer la poussée hypertensive duc à la laryngoscopie et à lin-

\section{Key words}

ANAESTHESIA: obstetrical;

INTUBATION: complications - cardiovascular;

PHARMACOLOGY: calcium channel blockers, nifedipine.

From the Departments of Anaesthesiology and Obstetrics and Gynaecology, Postgraduate Institute of Medical Education and Research, Chandigarh-160012 (India).

Address correspondence to: Dr. Y.K. Batra, Department of Anaesthesiology, PGI, Chandigarh-160012 (India). Accepted for publication 17th December, 1992. tubation endotrachéale a été évaluée chez trente femmes souffrant dhypertension d'origine gestationnelle $(P I H)$ et programmées pour une césarienne sous anesthésie générale. Les patientes ont reçu aléatoirement soit une gélule de $10 \mathrm{mg}$ de néfidipine, soit un placébo, par voie sublinguale, vingt minutes avant linduction de l'anesthésie. La pression artérielle et la fréquence cardiaque ont été enregistrées à des intervalles de temps variés. Il y a eu une diminution de la pression artérielle moyenne $(M A P)$ après le prétraitement à la néfidipine $(P<$ $0,01)$. L'augmentation de la MAP pendant la laryngoscopie et lintubation a été plus importante dans le groupe contrôle par rapport au groupe prétraité à la néfidipine $(P<0,01)$. Pendant la laryngocopie et lintubation, la MAP a diminué de $3 \mathrm{mmHg}$ dans le groupe prétraité à la néfidipine, tandis quill y a eu un accroissement de $14 \mathrm{mmHg}$ dans le groupe contrôlé. La fréquence cardiaque a augmenté dans les deux groupes lors de la laryngoscopie et de lintubation $(P<0,01)$ mais cette augmentation a été supérieure dans le groupe néfidipine $(P<0,05)$. Les scores d'Apgar dans les deux groupes étaient comparables. Les résultats suggèrent que la néfidipine en sublingual est efficace pour atténuer la région hypertensive mais pas la tachycardie lors de la laryngoscopie et lintubation chez les parturientes atteintes de PIH.

The pressor response to intubation is markedly exaggerated in hypertensive pregnant patients, with increases in systemic and pulmonary arterial pressures and pulmonary capillary wedge pressure. 1,2 Transient but severe hypertension during tracheal intubation has been associated with increased maternal intracranial pressure, cerebral haemorrhage and cardiac failure with pulmonary oedema, resulting in increased morbidity and mortality in both mother and child. ${ }^{3}$

Various drugs and techniques have been used to attenuate these haemodynamic responses but none has been shown to be superior. Nifedipine, a calcium channel blocker has been used in the management of non-gravid 
hypertension both acutely ${ }^{4}$ and in the long term. ${ }^{5}$ It has also been used to treat acute episodes of severe hypertension during pregnancy and puerperium without causing any adverse fetal effects. ${ }^{6}$

Nifedipine has been found to attenuate the reflex cardiovascular responses to laryngoscopy and tracheal intubation in normotensive patients. ${ }^{7}$ The present investigation was planned to study the effectiveness of nifedipine in attenuating the pressor responses associated with laryngoscopy and intubation in pregnancy-induced hypertensive patients undergoing Caesarean section.

\section{Methods}

The study was approved by the Human Ethics Committee of the Nehru Hospital PGIMER, Chandigarh and informed written consent obtained from all the patients.

Thirty women with pregnancy-induced hypertension (diastolic blood pressure of $100-120 \mathrm{mmHg}$ ) scheduled for Caesarean section under general anaesthesia were selected for the study. The patients were receiving treatment with antihypertensive drugs such as hydralazine and methyldopa. They were randomly assigned to control (Group I, $n=15$ ) or nifedipine groups (Group II, $n=15$ ) with random number charts. Patients with preexisting cardiorespiratory diseases, morbid obesity and diabetes were excluded from the study.

Twenty minutes before the induction of anaesthesia the patients were given either the contents of a nifedipine gelatin capsule $10 \mathrm{mg}$ or a placebo capsule of a similar physical characteristic sublingually by the fourth author who was not involved in rest of the study.

On arrival in the operating theatre, patients were placed supine with a $15^{\circ}$ left lateral tilt. A $5 \%$ dextrose infusion was started and the patients were preoxygenated for five minutes. Anaesthesia was induced rapidly in all the patients with thiopentone $5 \mathrm{mg} \cdot \mathrm{kg}^{-1}$, followed by succinylcholine hydrochloride $1.5 \mathrm{mg} \cdot \mathrm{kg}^{-1}$. Any patient in whom tracheal intubation proved to be difficult or who strained or coughed during intubation was excluded from the study.

Anaesthesia was maintained with 50:50 mixture of $\mathrm{N}_{2} \mathrm{O}$ and $\mathrm{O}_{2}$ until the delivery of the baby after which the $\mathrm{O}_{2}$ concentration was reduced to $33 \%$. Pancuronium bromide $0.07 \mathrm{mg} \cdot \mathrm{kg}^{-1}$ was the muscle relaxant used in all the patients.

The blood pressure and heart rate were recorded at the following intervals:

(A) Before nifedipine pre-treatment (Control value).

(B) Twenty minutes after pre-treatment, i.e., just before induction of anaesthesia.

(C) After injection of thiopentone.

(D) During laryngoscopy and tracheal intubation. E,F,G,H,I at one, two, three, five and ten minutes respectively following laryngoscopy and tracheal intubation.

Heart rate and blood pressure were monitored using a digital blood pressure meter (OMRON MODELHEM,58). The mean arterial pressure (MAP) was calculated using the formula diastolic blood pressure $+1 / 3$ pulse pressure. At delivery, the Apgar score of the baby, maternal blood gas values and $\mathrm{pH}$, induction-delivery and uterine incision to delivery intervals were also recorded.

Analysis of variance and Student's $t$ test were used to analyse changes within and between the groups. The Mann-Whitney test was used for analysing nonparametric data for Apgar score. $P<0.05$ was considered to indicate statistical significance.

\section{Results}

Age, weight, base line blood pressure and heart rate induction-delivery intervals, uterine incision to delivery intervals and preoperative antihypertensive medications were similar in the control and treatment groups (Table I).

The changes in MAP and heart rate in both groups during the induction sequence are presented in Figure 1 and Figure 2 respectively. There was a decrease in MAP after pretreatment with nifedipine in Group II $(P<0.01)$. In both groups MAP decreased after administration of thiopentone but there was no difference between the two groups at that time. The increase in MAP during laryngoscopy and intubation was greater in Group I than in Group II $(P<0.01)$. During laryngoscopy and intubation MAP decreased by $3 \mathrm{mmHg}$ from the basal value in Group II while there was an increase of 14 $\mathrm{mmHg}$ in Group I (Figure 1).

There was an increase in heart rate after pretreatment with nifedipine in Group II $(P<0.01)$ (Figure 2). During laryngoscopy and tracheal intubation there was an increase in heart rate in both the groups $(P<0.01)$ but the increase was greater in Group II and the difference between the two groups was statistically significant $(P$ $<0.05$ ). The increase in heart rate over the basal value at one minute after intubation was 27 beats per minute in Group II and 18 beats per minute in Group I. The heart rate was higher in Group II than that in Group I throughout the study period $(P<0.01)$ (Figure 2).

Maternal and arterial blood gas analysis at delivery were similar in both groups (Table II) and Table III illustrates the neonatal Apgar scores in both the groups were not different.

\section{Discussion}

Pregnancy-induced hypertensive patients require close control of blood pressure during anaesthesia for Caesarean section for both maternal and fetal well being. 
TABLE I Maternal variables in the control and nifedipine treatment groups (mean $\pm \mathrm{SD}$ )

\begin{tabular}{lcc}
\hline & $\begin{array}{c}\text { Control group } \\
(n=15)\end{array}$ & $\begin{array}{l}\text { Nifedipine group } \\
(n=15)\end{array}$ \\
\hline Age $(\mathrm{yr})$ & $27.2 \pm 4.0$ & $28.2 \pm 3.5$ \\
Weight $(\mathrm{kg})$ & $74.3 \pm 1.4$ & $75.4 \pm 1.5$ \\
Base line mean BP (mmHg) & $124.0 \pm 6.0$ & $128.0 \pm 8.0$ \\
Base line heart rate (bpm) & $90.0 \pm 11.0$ & $92.0 \pm 15.0$ \\
lnduction to delivery time (min) & $7.2 \pm 1.2$ & $6.6 \pm 1.2$ \\
Uterine incision to delivery & & \\
$\quad$ time (sec) & $64.5 \pm 12.7$ & $61.8 \pm 13.8$ \\
Pre-op drugs & & \\
- Methyldopa $(n)$ & 8 & 7 \\
- Hydralazine $(n)$ & 6 & 9 \\
\hline
\end{tabular}

No significant difference.

TABLE II Maternal arterial blood gas values

\begin{tabular}{lcc}
\hline & $\begin{array}{l}\text { Control group } \\
(n=15)\end{array}$ & $\begin{array}{l}\text { Nifedipine group } \\
(n=15)\end{array}$ \\
\hline $\mathrm{pH}$ & $7.4 \pm 0$ & $7.4 \pm 0$ \\
$\mathrm{PaO}_{2}(\mathrm{mmHg})$ & $145.6 \pm 16.3$ & $140.0 \pm 15.1$ \\
$\mathrm{PaCO}_{2}(\mathrm{mmHg})$ & $35.3 \pm 3.7$ & $35.6 \pm 4.6$ \\
$\mathrm{HCO}_{3}$ (meq $\left.\cdot \mathrm{L}^{-1}\right)$ & $23.0 \pm 3.1$ & $23.8 \pm 2.0$ \\
\hline
\end{tabular}

No significant difference.

TABLE III Newborn Apgar score (Mean \pm SD)

\begin{tabular}{lll}
\hline & $\begin{array}{l}\text { Control group } \\
(n=15)\end{array}$ & $\begin{array}{l}\text { Nifedipine group } \\
(n=15)\end{array}$ \\
\hline 1 Minute & $6.4 \pm 1.3$ & $6.2 \pm 1.4$ \\
& $(4-8)$ & $(3-8)$ \\
S Minute & $7.9 \pm 1.2$ & $8.2 \pm 1.3$ \\
& $(6-10)$ & $(5-10)$ \\
\hline
\end{tabular}

No significant difference.

Nifedipine, a dihydropyridine, is well absorbed by oral or sublingual routes. After a single sublingual administration of nifedipine $10 \mathrm{mg}$, an antihypertensive action is obvious within five to eight minutes with peak effect at 20 to 30 min. $^{8}$ It has been used to attenuate the cardiovascular responses to laryngoscopy and tracheal intubation in normotensive patients. ${ }^{7}$ It has also been used to treat acute episodes of severe hypertension during pregnancy and puerperium without any adverse fetal effects. ${ }^{6}$ Nifedipine has also been found to have beneficial effects on urinary output during the first $24 \mathrm{hr}$ postpartum in patients with severe eclampsia. ${ }^{9}$

In our study nifedipine smoothly and gradually reduced the SBP, DBP and MAP by approximately $10 \%$ of the control value within 20 min of sublingual administration. This smooth and gradual reduction mitigated

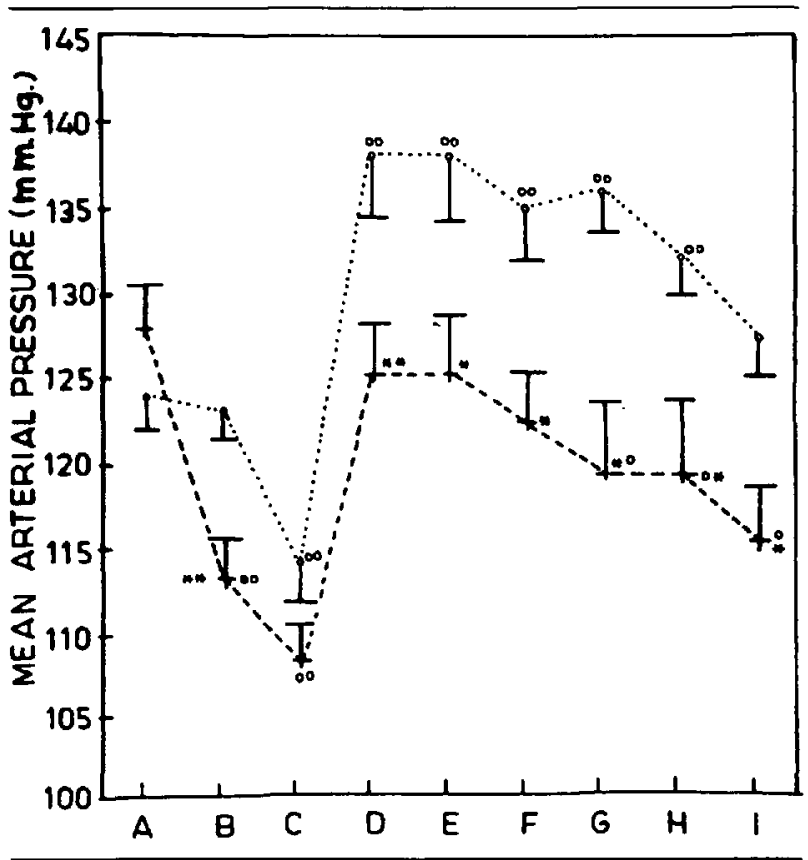

FIGURE 1 Mean arterial pressure (MAP) changes in control (Group I, $n=15 \ldots$ ) and nifedipine pretreatment (Group II, $n=$ $15 \ldots$... patients at various times. A - Before nifedipine pretreatment (control value); B - twenty minutes after pre-treatment; C - after thiopentone; $\mathrm{D}$ - During laryngoscopy and tracheal intubation, E,F,G,H,I - one, two, three, five and ten minutes after laryngoscopy and intubation. Within group comparison ${ }^{\circ} P<0.05,{ }^{\circ} P<0.01$. Between group comparison ${ }^{*} P<0.05,{ }^{* *} P \mathrm{a}<0.01$. (All values mean \pm SEM).

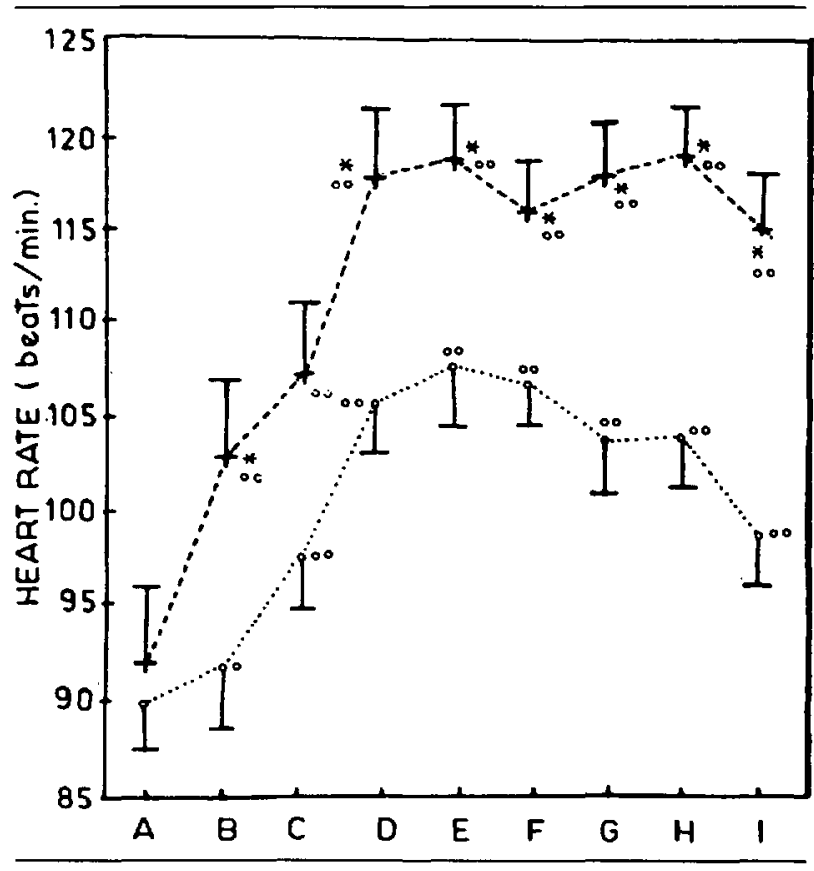

FIGURE 2 Heart rate changes in control ( ...) and nifedipine (...) treated patients at various time intervals. (All values mean \pm SEM.) For symbols see Figure 1. 
the risk of unintentional hypotension. This $10 \%$ reduction in blood pressure following sublingual nifedipine buffered the increase in blood pressure following endotracheal intubation in Group II.

An increase in heart rate was observed in the patients treated with nifedipine. The heart rate during laryngoscopy, one minute and two minutes after laryngoscopy was higher $(P<0.05)$ in Group II than in Group I. In previous studies where nifedipine was used to attenuate the cardiovascular responses to laryngoscopy and tracheal intubation in normotensive ${ }^{7}$ and in patients with coronary artery disease, ${ }^{10}$ there was an increase in heart rate in both groups but the heart rates of the control group did not differ from the nifedipine group at any time during the investigation. This discrepancy in heart rate compared with our study could be explained because the central venous pressure in PIH is low and varies inversely with the severity of hypertension. ${ }^{11,12}$ Plasma volume in PIH is $10 \%$ less than in normal pregnant women. " This diminished intravascular volume leads to increased baroreceptor activity and augmentation of sympathetic nervous system activity. ${ }^{11}$ Moreover, nifedipine by virtue of its blood pressure lowering effects activates baroreceptors leading to an increased heart rate. ${ }^{13}$ Both of these factors might have been responsible for the greater increase in heart rate seen in Group II patients compared with Group I. It is also possible that the haemodynamic response which persisted after intubation can be due to the added effect of both intubation and surgical stimuli.

Many other drugs have been tried to attenuate the hypertensive response to tracheal intubation in PIH patients. The relatively slow onset and long duration of action of hydralazine prevents rapid adjustment of blood pressure. ${ }^{14}$ Trimethaphan acts rapidly ${ }^{15}$ and has a short duration of action but may prolong muscle paralysis after succinylcholine. ${ }^{16}$ Other undesirable side effects of trimethaphan include histamine release, reduction of splanchnic blood flow and cardiac output. ${ }^{15}$ Sodium nitroprusside also has a rapid onset of action but carries the risk of both maternal and fetal cyanide toxicity. ${ }^{17}$ It also increases maternal intracranial pressure. ${ }^{18}$ Nitroglycerine has been found to be effective in preventing the hypertensive response but it crosses the placenta and may also increase maternal intracranial pressure. ${ }^{19}$

In a preliminary study intravenous labetalol pretreatment had been evaluated to attenuate the pressure response to laryngoscopy and intubation with moderate success. ${ }^{20}$ The disadvantage of labetalol pretreatment was that in the event of sudden excessive blood loss, patients might not be able to compensate by an increase in heart rate and peripheral vascular resistance. Moreover, labetalol can cause neonatal bradycardia and hypotension. ${ }^{21}$

In the present study two patients in Group II com- plained of headache. No other adverse effect was noticed. The Apgar scores were comparable in both groups and no adverse neonatal effects were noted in our study.

In conclusion, sublingual nifedipine when employed as a pretreatment in a dose of $10 \mathrm{mg}$ attenuates the hypertensive response but not the tachycardic response to laryngoscopy and tracheal intubation in PIH patients.

\section{References}

1 Hodgkinson R, Husain FJ, Hayashi RH. Systemic and pulmonary blood pressure during Caesarean section in parturients with gestational hypertension. Can Anaesth Soc J 1980; 27: 389-94.

2 Connell H, Dalgleish JG, Downing JW. General anaesthesia in mothers with severe pre-eclampsia/eclampsia. Br J Anaesth. 1987; 59: 1375-80.

3 Lawes EG, Downing JW, Duncan PW, Bland B, Lavies N, Gane $G A$. Fentanyl-droperidol supplementation of rapid sequence induction in the presence of severe pregnancyinduced and pregnancy-aggravated hypertension. $\mathrm{Br} \mathrm{J}$ Anaesth 1987; 59: 1381-91.

4 Kawajima I, Uedai $K$, Kamata $C$, et al. A study on the effects of nifedipine in hypertensive crises and severe hypertension. Jpn Heart J 1978; 19; 455-67.

5 Guazzi MD, Fiorentini $C$, Olivari $M T$, Bartorelli $A$, Necchi $G$, Polese $A$. Short- and long-term efficacy of a calciumantagonistic agent (nifedipine) combined with methyldopa in the treatment of severe hypertension. Circulation 1980; 61: 913-9.

6 Walters BNJ, Redman CWG. Treatment of severe pregnancy-associated hypertension with the calcium antagonist nifedipine. Br J Obstet Gynecol 1984; 91: 330-6.

7 Puri GD, Batra $Y K$. Effect of nifedipine on cardiovascular responses to laryngoscopy and intubation. $\mathrm{Br} \mathrm{J}$ Anaesth 1988; 60: 579-81.

8 Guazzi $M$, Olivari MT, Polese A, Fiorentini C, Magrini $F$, Moruzzi $P$. Nifedipine, a new antihypertensive with rapid action. Clin Pharmacol Ther 1977; 22: 528-32.

9 Barton JR, Hiett AK, Conover WB. The use of nifedipine during the postpartum period in patients with severe preeclampsia. Am J Obstet Gynecol 1990; 162: 788-92.

10 Kale SC, Mahajan RP, Jayalakshmi, Raghavan V, Das B. Nifedipine prevents the pressure response to laryngoscopy and tracheal intubation in patients with coronary artery disease. Anaesthesia 1988; 43: 495-7.

11 Wright JP. Anesthetic considerations in preeclampsiaeclampsia. Anesth Analg 1983: 63: 590-601.

12 Rafferty $T D$, Berkowitz RL. Haemodynamics in patients with severe toxemia during labor and delivery. Am $\mathbf{J}$ Obstet Gynecol 1980; 138: 263-70.

13 Jones RM. Calcium antagonists. In: Atkinson RS, Adams AP (Eds.). Recent Advances in Anaesthesia and Analgesia. 15 London. Churchill Livingstone, 1986; 89-106. 
14 Gerber JG, Nies AS Hydralazine. In: Gilaman AG, Goodman LS (Eds.). The Pharmacological Basis of Therapeutics. New York: MacMillan. 8th ed. 1991; 799-801.

15 Taylor $P$. Agents acting at the neuromuscular junction and autonomic ganglia. In: Gilman AG, Goodman LS (Eds.). The Pharmacological Basis of Therapeutics. New York: MacMillan. 8th ed. 1991; 166-86.

16 Poulton TJ, James FM, Lockridge O. Prolonged apnea following trimethaphan and succinylcholine. Anesthesiology 1979; 50: 54-6.

17 Naulty J, Cefalo RC, Lewis PE. Fetal toxicity of nitroprusside in the pregnant ewe. Am J Obstet Gynecol 1981; 139: 708-11.

18 Shoemaker $C T$, Meyers $M$. Sodium nitroprusside for control of severe hypertensive disease of pregnancy: a case report and discussion of potential toxicity. Am J Obstet Gynecol 1984; 149: 171-3.

19 Hood DD, Dewan DM, James FM, Floyd HM, Bogard $T D$. The use of nitroglycerin in preventing the hypertensive response to tracheal intubation in severe preeclampsia. Anesthesiology 1985; 63: 329-32.

20 Ramanathan J, Sibai BM, Mabie WC. The use of labetalol for attenuation of the hypertensive response to endotracheal intubation in pre-eclampsia. Am J Obstet Gynecol 1988; 159: 650-4.

21 Macpherson $M$, Bronghton Pipkin F, Rutter $N$. The effect of maternal labetalol on the newborn infant. Br J Obstet Gynecol 1986; 93: 539-42. 